labor involved in the attempt to rearrange this vast complex with its varying, and in some instances apparently antagonistic lines of development in the adult and immature stages. The faunal region covered is broader than that which falls to most investigators and moreover there have been exceptional opportunities for special collecting in a number of representative areas.

E. P. Felt.

\title{
NOTE OF CORRECTION (HEMIPTERA).
}

Psyche, 1914, Vol. 21, List Hem.-Het. of Maine:

In this article are a number of errors of determination, etc., which are corrected in my New England list recently published in the Occasional Papers of the Boston Society of Natural History.

Psyche, 1915, Vol. 22, Synop. Families:

P. 90, line 3 from bottom: "rostrum 3-segmented" should read rostrum 4-segmented.

Ib., Synop. Pentatomidæ:

P. 172, line 20 from bottom: " 17 " should read 16; line 8 from bottom: "14" should read 15.

P. 173, line 20 from bottom: " 16 " should read

1. Peribalus. Delete the next three lines and substitute:

16. Juga much longer than tylus.......19. Dendrocoris.

Juga not much longer than tylus..............17

Ent. News, 1915, Vol. 26, Ext. Anat. A. rapidus, etc.:

P. 212, "embolim" should read embolium.

Psyche, 1917, Vol. 24, Notes on N. Am. Tingidæ:

P. 24, The holotype of Hesperotingis fuscata Parsh. is in de la Torre Bueno's collection, not in Barber's.

For other corrections see Psyche, 1915, Vol. 22, p. 220.

H. M. Parshley. 

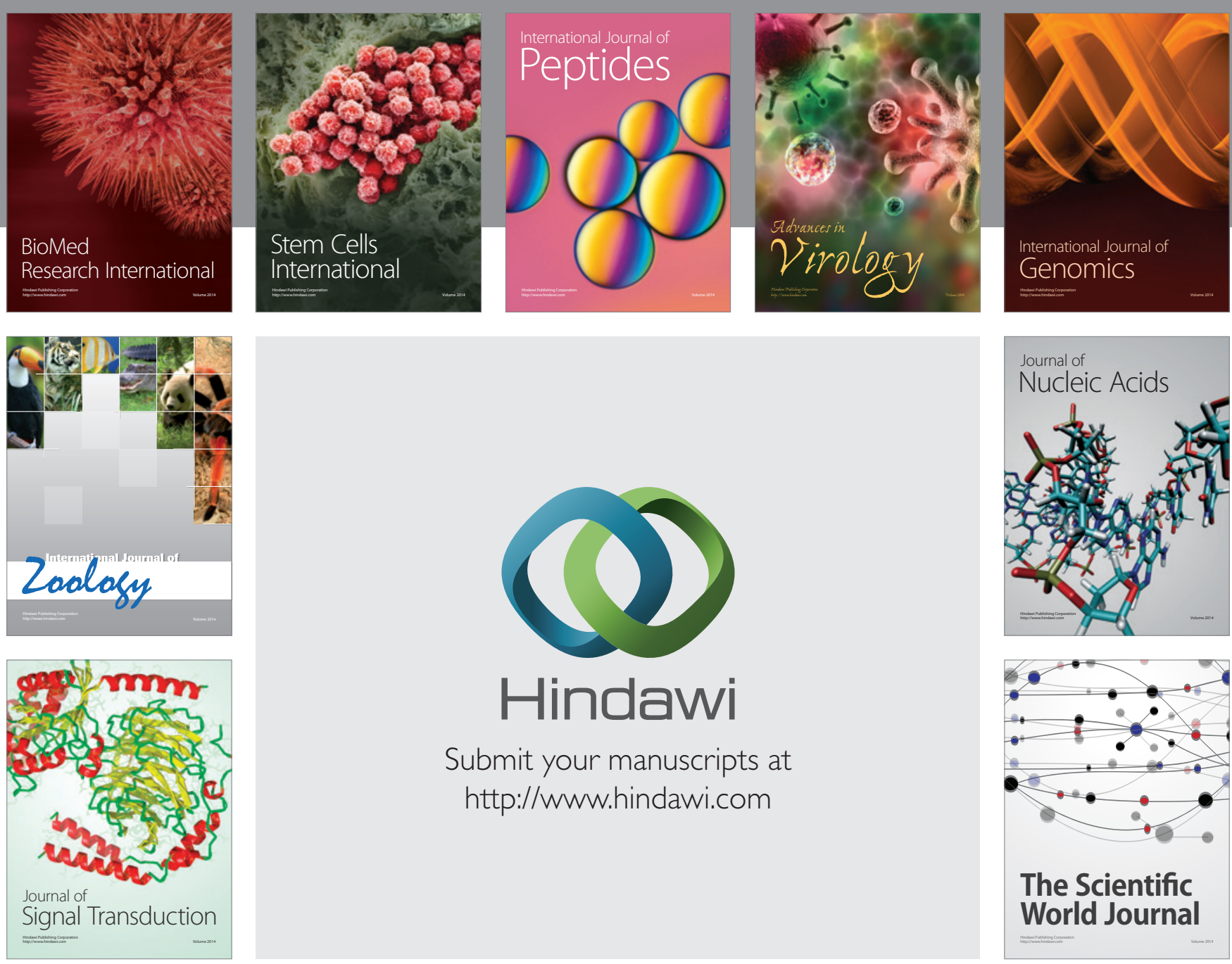

Submit your manuscripts at

http://www.hindawi.com
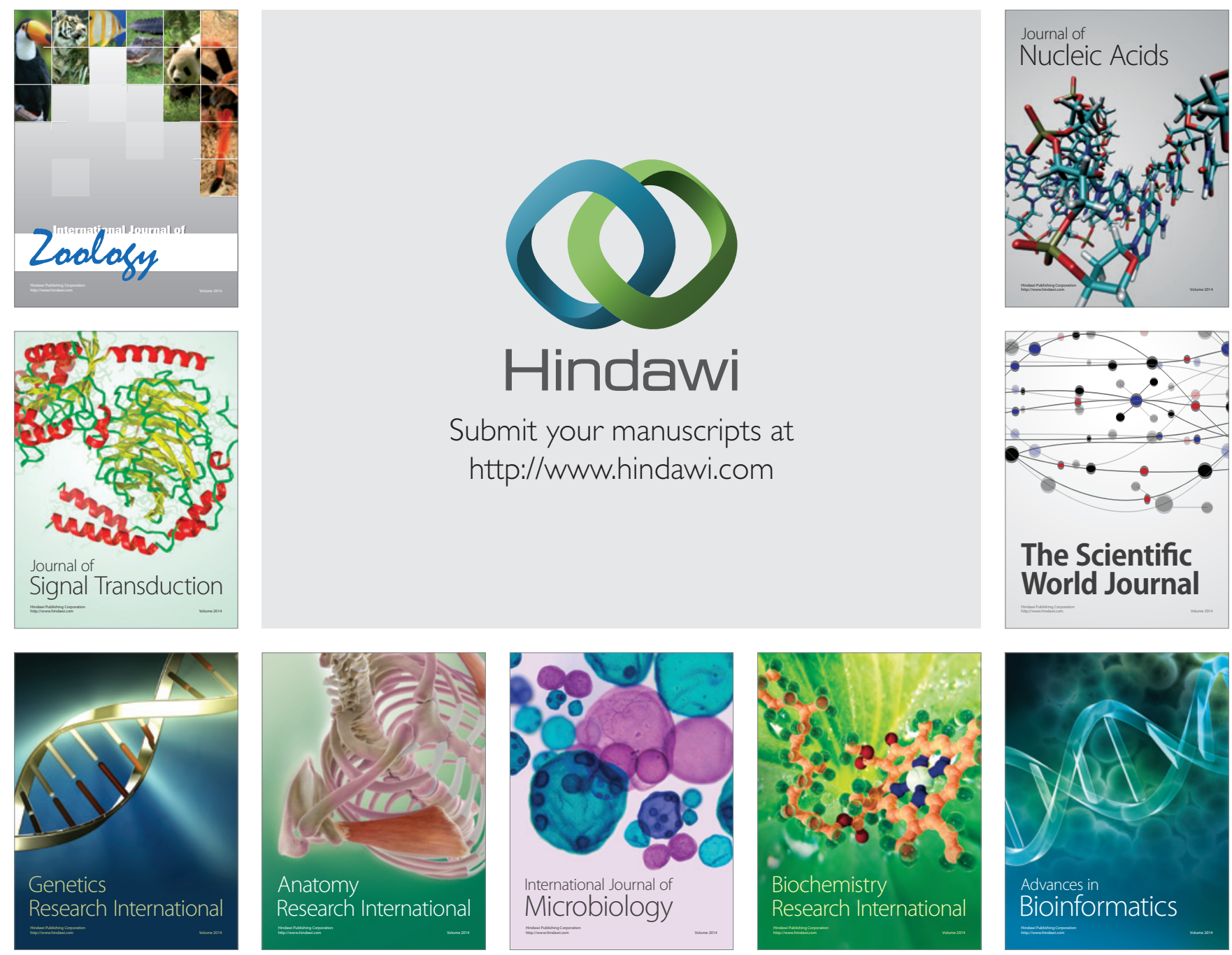

The Scientific World Journal
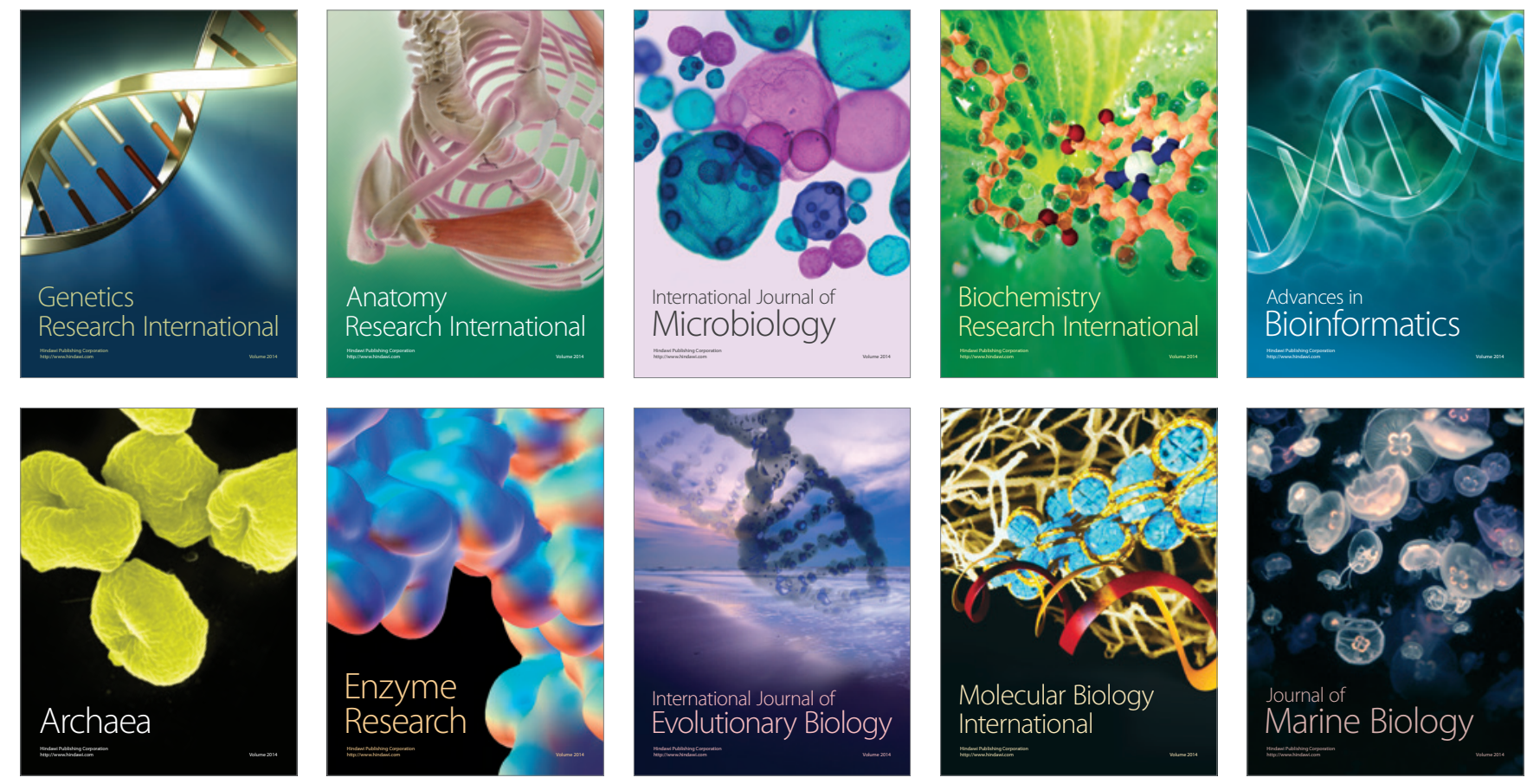